\title{
Power Quality Issues in Power Systems
}

\author{
Ravikanth Mallajoshula, I.E.S. Naidu
}

\begin{abstract}
Power quality in power system is one of the most important researches in the recent age, many researchers working in this area keeping objective to achieve quality power. This paper presents power quality issues in power systems, especially in INDIA. It also includes the various causes of power quality problems, their impact and precautionary measure to solve the power quality issues. Various mitigating devices used to solve various power quality problems and some methods suggested improving the power quality. Different types of controller and their specific applications also presented. A Hybrid APF designee is also suggested to mitigate the harmonics in power lines. Finally, the paper is designed to give an overview of power quality phenomenon in power system and can be utilized by the researchers those working in the area of power quality.
\end{abstract}

Keywords: Power Quality, Interruption, Harmonics, Sag, Controller etc.

\section{INTRODUCTION}

Different professional organization defines the term Power Quality in different ways. IEEE-Std 1100 provides the power quality definition considering the powering and grounding of sensitive equipment so that operation taking place smoothly [1], IEC 61000 defines the term power quality taking consideration the electromagnetic compatibility of equipment so that it can work satisfactory in electromagnetic surroundings [1-3]. Time to time the definition of power quality also changing progressively and instead of power quality people are taking about Voltage quality and current quality. Quality power delivered to the consumers In the recent age degrades rapidly due to the vast application of power semiconductor devices. This motivates the researchers again to do the research in this area though the term was previously used in the field of Electrical Engineering. Modern power systems associated with many power semiconductor devices. These power semiconductor devices are problems of the power systems and also solution of the power system. The various loads in the power system is the power semiconductor devices which is treated as non linear load in the power system [1-3]. This non linear load develops unwanted signal termed as harmonics. This harmonics signal with fundamental gives rise to a distorted signal at a point in the line where other equipments connected. This distorted wave form is treated as the input of all the equipments connected to the same point of common coupling [1-3]. This equipment is designed to take the pure sinusoidal voltage but unfortunately they are getting distorted input which hampers their operation and develops unnecessary effects in the system. [4-5]. Power quality is not

Revised Manuscript Received on December 13, 2019.

* Correspondence Author

Ravikanth Mallajoshula, EEE department, Sreenidhi institute of science and technology, Hyderabad, India. Email: ravikant235@gmail.com

I.E.S Naidu, Associate Professor, Department of EECE, GITAM University, Vishakhapatnam, India. Email:iesnaidu@gmail.com the recent issue, this issue reflected in the year 1968. In this year one paper published related to the power requirement by various electronics equipments used in the United States navy [66]. This paper introduces the term Power quality using different types of monitoring equipment and also suggested the remedies for the cause. After that several papers came in to the area of power quality related to power system [1]. In the year 1970, one paper published keeping the view of Power quality in industrial sector along with safety and reliable factor and also this paper gives how to go for low initial and operating cost while designing the system for industry. In the same year analysis of Voltage Quality used by different authors in the Soviet Union [6]. After that several publications related to power quality came during 1968 to 1985 and after that 1986-1997.INSPEC keeps the record of work related to Power Quality and Voltage Quality [7-11]. Voltage disturbances and its increase sensitivity not only hamper the operation of electronics components but also hamper the production rate in the industry give rise to less profit [12]. Unnecessary tripping due to supply voltage disturbance is also term as bad power quality by the customer. Power semiconductor component not only sensitive to voltage disturbance but also a problem to other consumers. The demand on converter based equipment such as high speed adjustable drives, computers and other consumer used electronics components leads to large disturbances in the voltage [13]. The term interru12ption also part of a power quality which forces the utility to pay the customers if they have more interruption estimated by one year. Utility must be consider the consumers as their customers and try to find out a solution to reduce the number of interruption. If this thing not carried out in a proper way, this again invites privatization and deregulation of Electricity Company. Utilities drive the power quality problems and try to deliver good product to the consumers. To design a reliable system with low cost is one of the technical issues which need to be focused for betterment of power industry. Terms like voltage Sag and harmonics distortion also related to power quality and research is going on in this to minimize. Most industrialized country like Europe, East Asia has very less number of long interruptions, there is tremendous increase of publication in this area and also more focus is given on power quality instead of voltage quality [8-9]. Many Papers described the term voltage quality only concentrated on voltage not current distortions and especially it is interpreted that quality power is delivered to the customers from the utility [14-15]. Power quality is the result of both voltage and current quality [4,7] and is caused by the deviation of either voltage or current from its ideal [1]. In this paper, Section 1 describes an introduction to power quality. 


\section{Power Quality Issues in Power Systems}

Section II presents the Indian power quality Issues. Section III presents the harmonics in power systems mitigating techniques of various parameters. Section IV presents suggested techniques, 1) Unit vector template control technique and 2) Hybrid AP Filter with FPGA technique, to improve the power quality in power systems. Section V includes mitigation of harmonics by hybrid AP filters and Section VI Presents the conclusions.

\section{POWER QUALITY DISTURBANCE}

Deviation of voltage waveform from its original wave form and deviation of current from its original wave form termed as Power Quality Phenomenon or Power quality disturbance in the power systems. Power quality disturbance is broadly comes under two category. voltage and current characteristics which is not equal to the actual or nominal value indicates variation of frequency and power factor[1] and sudden deviation of voltage and current due to any events make the voltage zero[4] and flow of heavy distorted current when the transformer is energized without load. Voltage magnitude variation is the result of increasing or decreasing the magnitude of voltage due to various reasons such as load variation in distribution system, Setting of Tap changer in the Transformer and switching action of the capacitor and reactor etc. Voltage frequency variation which refers to power frequency variation by IEC is the result of mismatch of power generation capacity and the load demand. The supply voltage fails to maintain the constant frequency [4] current magnitude variation is also related to power quality phenomenon. The variation of voltage is the result of variation of current, as the current not maintains a constant magnitude throughout operation of a system.

All Interruption is one of the most important terms related with power quality, term like short interruption, momentary interruption and long interruption comes under this category [16-17].

Any In India the central electricity authority is authorized to look after the power quality issues, In 2015, Power grid conducted a survey on power quality by taking various data at GRID level including its own substations and Five regions such as North, South, Western, East and north east which covers the country power sectors. Measurement is carried out by using 3-Phase power quality analyzer within duration of 6 hours to 24 hours at each feeder including HV/EHV AND UHV with respect to the Current transformer and potential transformer. [3-4]. From the Table it can be easily understood that Power quality Phenomena are the results of parameter given below in the Table.1. The numbers mentioned below exceeds the permissible limit fixed by Central Electricity [3-4]. Critical power Quality parameters in various region in India is presented in Table. 2

Table- I Power quality analysis in INDIA

\begin{tabular}{|l|l|l|}
\hline $\begin{array}{l}\text { S1 } \\
\text { no }\end{array}$ & $\begin{array}{l}\text { Power Quality Analysis in Indian Power Sector } \\
\text { by considering various parameter }\end{array}$ & $\begin{array}{l}\text { Number } \\
\text { including } \\
\text { every } \\
\text { region[5] in } \\
\text { INDIA }\end{array}$ \\
\hline 1 & Total Number of Voltage Sag & 75 \\
\hline 2 & Total Number of Voltage Swell & 13 \\
\hline 3 & Total Number of Voltage Harmonics & 67 \\
\hline 4 & Total Number of Current Harmonics & 39 \\
\hline
\end{tabular}

\begin{tabular}{|l|l|l|}
\hline 5 & Total unbalanced Condition & 81 \\
\hline 6 & Total Number of DC Offset & 11 \\
\hline 7 & Total Number of Interruption & 11 \\
\hline
\end{tabular}

Table-II Critical parameter in different regions

\begin{tabular}{|l|l|l|}
\hline $\begin{array}{c}\text { S1 } \\
\text { no }\end{array}$ & Power Sector Region & Serious Power Quality Parameter \\
\hline 1 & Eastern & Voltage Harmonics and Voltage Sag \\
\hline 2 & Western & Voltage and Current Harmonics \\
\hline 3 & Northern & Voltage unbalance and Voltage Sag \\
\hline 4 & Southern & Voltage and Current Harmonics \\
\hline 5 & Northeastern & Voltage unbalance and Voltage Sag \\
\hline
\end{tabular}

\section{VARIOUS MITIGATION SOLUTIONS}

There are various power quality disturbances in the power systems [19], so it is crucial to maintain the power quality in power system by using different types of Techniques depending on the nature of the problems. If the problems are related to harmonics then harmonics filters is the main mitigating devices. In early seventy for elimination of harmonics Low pass filters were used and consequently there is an evolution of harmonics filters such as shunt, series and hybrid. [20]. If the problem is related to Sag, then constant voltage Transformer was used as the restoring devices [19-21]. Now various controllers have already been developed to solve the voltage sag problem with system interference equipments. Noise filters, static VAR Compensators also used for various papooses [13]. Various mitigating equipment used for various power quality problems are presented in Table-III.

Table-III Power quality issues and respective measures

\begin{tabular}{|c|c|c|}
\hline $\begin{array}{l}\text { S1 } \\
\text { no }\end{array}$ & $\begin{array}{l}\text { Power Quality } \\
\text { Parameter }\end{array}$ & Mitigating Measures \\
\hline 1 & Harmonics & $\begin{array}{l}\text { Passive or Active arrangement. } \\
\text { Passive: Series line reactor, tuned } \\
\text { filter, induction filter, resonance filter } \\
\text { etc. } \\
\text { Active: Shunt Filter, Series Filter, } \\
\text { Hybrid Filter etc }\end{array}$ \\
\hline 2 & $\begin{array}{l}\text { Voltage Sag and } \\
\text { Swell }\end{array}$ & $\begin{array}{l}\text { Installation of Protecting devices in } \\
\text { between process and grid, Constant } \\
\text { Voltage Transformer, Dynamic } \\
\text { Voltage Restorer, UPS,STATCOM, } \\
\text { Fly wheels etc, }\end{array}$ \\
\hline 3 & $\begin{array}{l}\text { Voltage } \\
\text { Interruption }\end{array}$ & $\begin{array}{l}\text { Using Energy storage system at the } \\
\text { end user, UPS etc }\end{array}$ \\
\hline 4 & $\begin{array}{l}\text { Under Voltage } \\
\text { and Over Voltage } \\
\text { Condition }\end{array}$ & $\begin{array}{l}\text { Shunt capacitor, Shunt Reactor, SVC, } \\
\text { STACTCOM and Tap setting of } \\
\text { Transformer etc }\end{array}$ \\
\hline 5 & Transients & $\begin{array}{l}\text { Surge Arrestor, Transient Voltage } \\
\text { Surge Suppressor, Voltage stabilizer, } \\
\text { Voltage Regulator etc. }\end{array}$ \\
\hline 6 & Voltage Notching & $\begin{array}{l}\text { Series connection of impedance } \\
\text { reactor with source }\end{array}$ \\
\hline 7 & $\begin{array}{l}\text { Voltage } \\
\text { Fluctuation }\end{array}$ & $\begin{array}{l}\text { Dynamic voltage regulators, } \\
\text { synchronous machines, STATCOM } \\
\text { etc. }\end{array}$ \\
\hline
\end{tabular}

\section{SUGGESTED MITIGATING TECHNIQUES}

\section{A. Unit Vector Template Control Techniques}

Though several mitigating methods adopted for improvement of power quality in power system, still there is a scope to implement different types of 
technique to achieve the objective. We can adopt various methods from starting of the generation to distribution through transmission of power system network. First is to reduce the number of faults using different types of measures, if precautionary measure is not taken then these faults leads to Sag and Interruption. Now a day's over head line is more used in both transmission and distribution. Replacement of overhead line by underground cable reduces the fault rate which is the results of bad weather condition or other external influences [21]. During heavy load period if there is contact between tree branch and the conductors fault will lead to interruption. Increase in the level of insulation and frequency of maintenance results of lesser faults. Fault clearing time also plays an important role in power quality issue. Though reducing the fault clearing time the duration of the Sag can be reduced and avoids adverse effect. Current limiting fuses can be utilized to reduce the fault clearing time [23-24]. Static breakers also other alternatives for reduction of fault clearing time. Implementation of changes in the supply system by incorporating generators near the sensitive load, splitting of buses in the substation in the path of supply, placing of current limiting coils in different places to maintain the fault distance etc reduce the sag problem and hence fault. Installing of compensating equipment such as UPS, M-G set, Voltage source converter etc increases the system performance by reducing the faults. Connection of capacitor banks to the internal dc bus of electronics equipments such as computer, laptop etc increases the immunity of the equipments and hence able to operate during occurrence of Sag. Improvement of inverter and rectifier design is needed to control the adverse effect in a dc drives due to sag. Addition of capacitance in the armature winding increases the immunity $f$ dc drives also.

Recent development for mitigation of Voltage sag and Interruption is done by placing of converters between system and equipment. The converters principle based on injection of active power and compensates the loss of active power coming from the system. Power conditioners, Active filters, compensator, controllers etc are all similar kind of components used to improve the power quality. The FACTS devices also come under voltage source converter $[1,26]$. Series voltage controller used to solve the sag problem. It consists of a voltage source converter in series with the supply. It operate on the principle of

$$
V_{\text {Load }}=V_{\text {Controller }}+V_{\text {Sag }}
$$

The controller will inject the active power filter by calculating the energy requirement from the below expression.

$$
P_{\text {Controller }}=(1-V) \times P_{\text {Load }}
$$

The active power required by the controller is depends on the drop of voltage and hence sag problem can be overcome.

Limitation of reactive power fluctuation and current harmonics is taking care by Shunt controller. In this controller a current is injected which boost the voltage at the load terminal. Due to the injected current the required change in voltage at the load terminal is presented by referring [26]

$$
\Delta V=1-V \operatorname{Cos} \psi-j V \operatorname{Sin} \psi
$$

The injection of the Active power in this controller

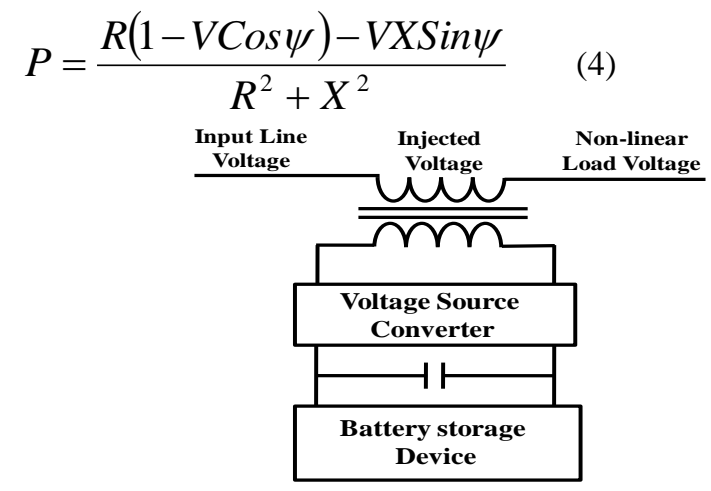

Fig.1 Series Controller

Though both series and shunt controller are used to mitigate the voltage both have some disadvantage [27]. This problem can be overcome by the combined controller which constitutes both series and shunt. It operates on the principle of power taken by the shunt one is equal to the power injected by the series controller [28]. In this controller the shunt controller can be placed in source side as well as load side. The shunt controller connected to system side will inject a current followed by equation 5 and the shunt controller connected to the load side inject current as per equation. 6

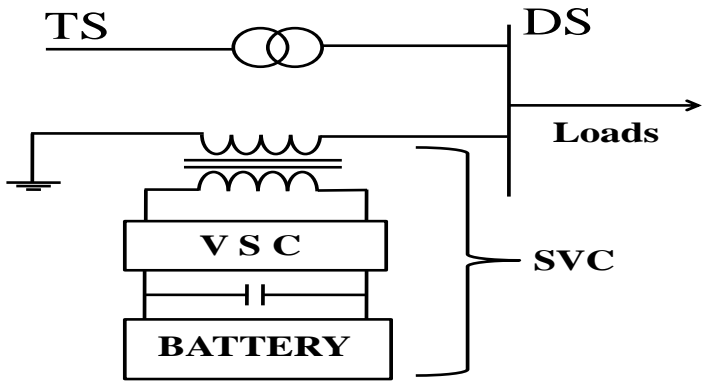

Fig.2 Shunt Controller

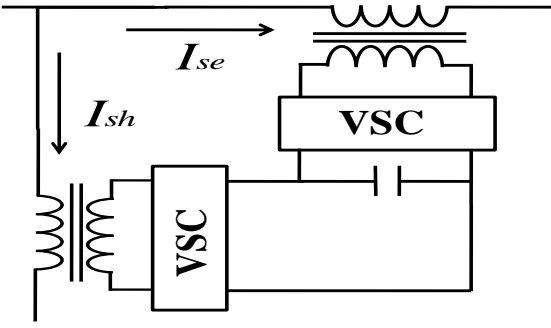

Fig.3 Combined controller Shunt Converter source side

$$
I_{\text {Shunt }}=\left[\frac{1}{V}-\frac{\operatorname{Cos}(\phi+\psi)}{\operatorname{Cos} \phi}\right] \times P_{\text {Load }}
$$

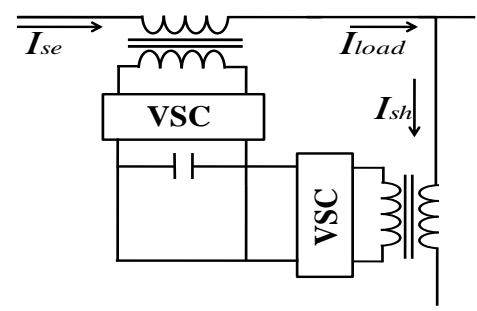

Fig.4 Combined controller Shunt Converter in the Load side 
Power Quality Issues in Power Systems

$$
I=\frac{1}{V}-\frac{\operatorname{Cos}(\phi+\psi)}{\operatorname{Cos} \phi}
$$

\section{B. Hybrid AP Filter with FPGA technique}

A shunt active filter acts as a source current to inject harmonic components of current to suppress the harmonics generated by non linear loads. The basic configuration of VSI shown in figure5. The main operating principle is to generate compensating current $\left(i_{c c}\right)$ to nullify distorted current, which can be achieved through Voltage source inverter. Technically, the compensating current $\left(i_{c c}\right)$, from figure shown below, can be obtained as $i_{i}=i_{\text {load }}-i_{c c}$,

$$
i_{c c}=i_{\text {load }}-i_{i}
$$

The fundamental current $\left(i_{f l}\right)$ and the harmonic current $\left(i_{h l}\right)$ in the Non-linear load is summed up as

$$
i_{\text {load }}=i_{f l}+i_{h l}
$$

So the injected compensation current by this filter is obtained as $\boldsymbol{i}_{c c}=\boldsymbol{i}_{h l}$, and input current is $\boldsymbol{i}_{i}=\boldsymbol{i}_{f l}$, contains only the fundamental current which is free from harmonics. A New Hybrid-APF is shown in figure.5. It is consisting of an AC source connected to power lines to a Non-Linear load. The lines are controlled by a full bridge VSI with shunt capacitor and also parallel passive filter. The gate terminals of VSI are switched through SDA [29]. The simulation output results are carried out in MATLAB R2014a, Table.4, and the experimental results, Table.5, are tested with FPGA on Xilinx system generator [29] are compared and tabulated.

The system setup results are carried out by taking input voltage of $230 \mathrm{~V}, 50 \mathrm{~Hz}$ while the load connected to it is harmonics generated by R-L diode rectifier, shown in figure5. To obtain the gating signals for IGBTs, an algorithm is implemented and further processed by XILINX system generator [29]. Field programmable gate array provides the required gating signals and is fed to the Hybrid filter to mitigate the harmonics generated by nonlinear loads.

The complete block diagram of system setup is shown in figure. 6 followed by experimental verification and tabulated values

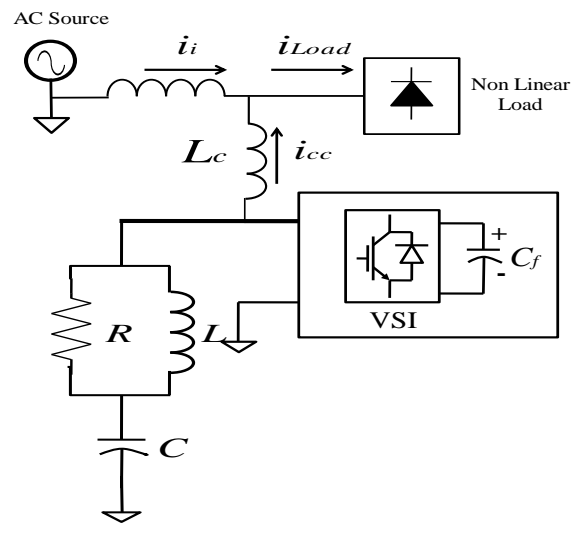

Fig.5 Hybrid APF

TABLE-IV Values of MATLAB simulations

\begin{tabular}{|l|l|l|}
\hline $\begin{array}{l}\text { Sl } \\
\text { no }\end{array}$ & Network Parameter & $\begin{array}{l}\text { Values } \\
\text { measuring }\end{array}$ \\
\hline 1 & Frequency & $50 \mathrm{~Hz}$ \\
\hline 2 & Line Voltage & $230 \mathrm{~V}$ \\
\hline 3 & Load Impedance & $5 \mathrm{KW}$ \\
\hline 4 & DC voltage(ref) & $670 \mathrm{~V}$ \\
\hline 5 & DC bus capacitor & $1 \mathrm{~K} \mu \mathrm{F}$ \\
\hline 6 & PI controller gain & 0.3 \\
\hline 7 & Line Impedance & $2.5,0.3$ \\
\hline 8 & APF inductance & $1 \mathrm{mH}$ \\
\hline
\end{tabular}

TABLE-V SYSTEM SETUP VALUES

\begin{tabular}{|l|l|l|}
\hline $\begin{array}{l}\text { Sl } \\
\text { no }\end{array}$ & $\begin{array}{l}\text { Network } \\
\text { Parameter }\end{array}$ & Values measuring \\
\hline 1 & $\begin{array}{l}\text { Voltage and } \\
\text { Frequency }\end{array}$ & $230 \mathrm{~V}, 50 \mathrm{~Hz}$ \\
\hline 2 & Load AC power & $5 \mathrm{KW}$ \\
\hline 3 & Source Impedance & $2.5 \mathrm{Mh}, \mathrm{Rs}=0.3 \Omega$ \\
\hline 4 & DC voltage(ref) & $670 \mathrm{~V}$ \\
\hline 5 & DC bus capacitor & $2.2 \mathrm{~K} \mu \mathrm{F}$ \\
\hline 6 & Non-linear load & $1.2 \mathrm{KV}, 60 \mathrm{~A}$ \\
\hline 7 & Sampling time & $15 \mathrm{KHz}$ \\
\hline 8 & FPGA & SPARTAN 6 \\
\hline 9 & Software & XILINX 14.2 \\
\hline
\end{tabular}

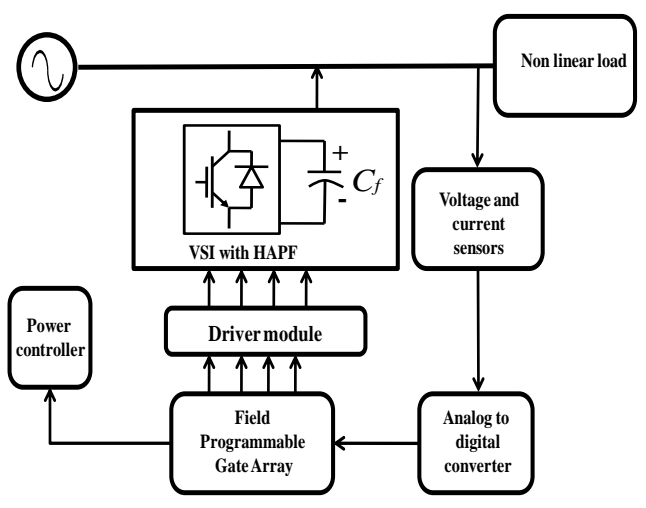

Fig.6 Block diagram of proposed system setup

\section{SIMULATION AND EXPERIMENTAL SETUP RESULTS}

The output results obtained by carrying out the simulations are shown below. Figure7. 


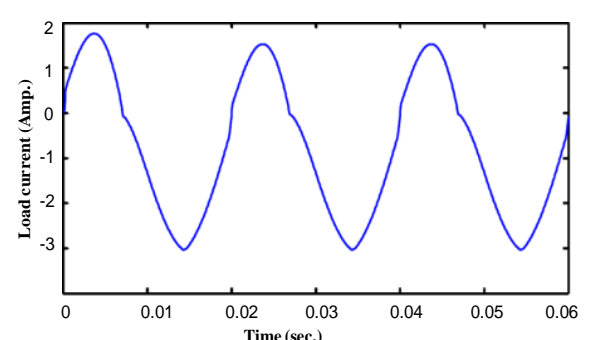

Fig.7 Simulated wave form of load current

The output load current obtained by simulations shows the satisfactory results of the proposed Hybrid AP filter. Also, observer the source current verses for the same time samples, shown in Figure.8.

The total harmonic distortion shown in Figure.9 is obtained after compensation of harmonics by sending the compensating signal into the system.

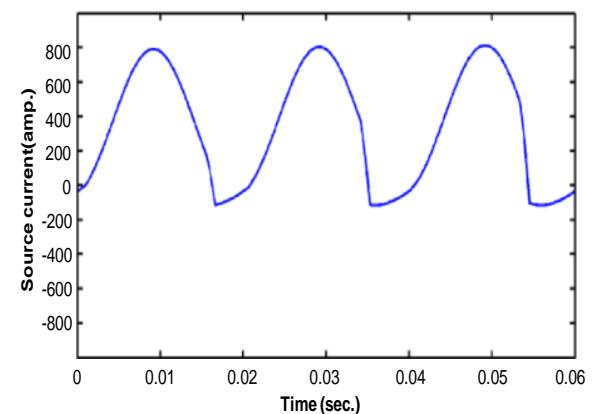

Fig.8 Simulated wave form of source current

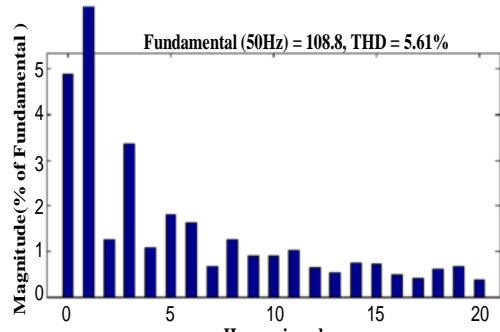

Fig.9 FFT Analysis of Source current

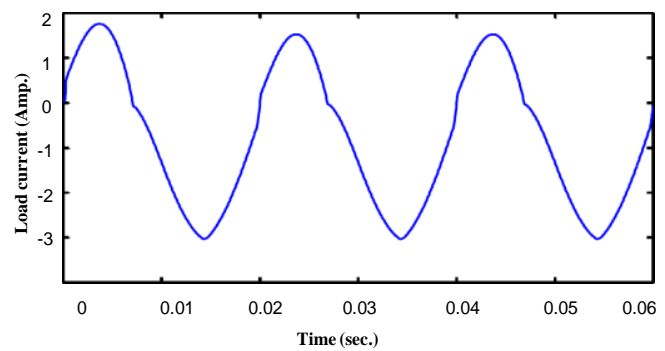

Fig.10 Simulated wave form of load current

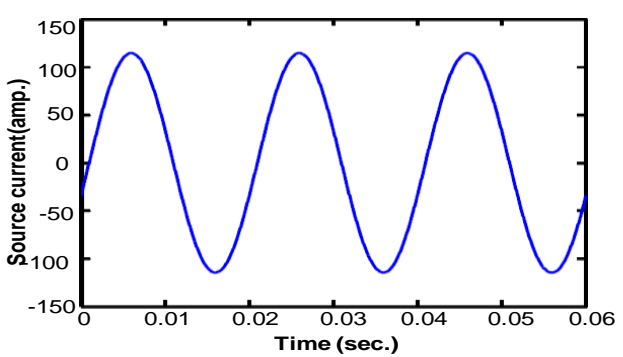

Fig.11 Simulated wave form of source current

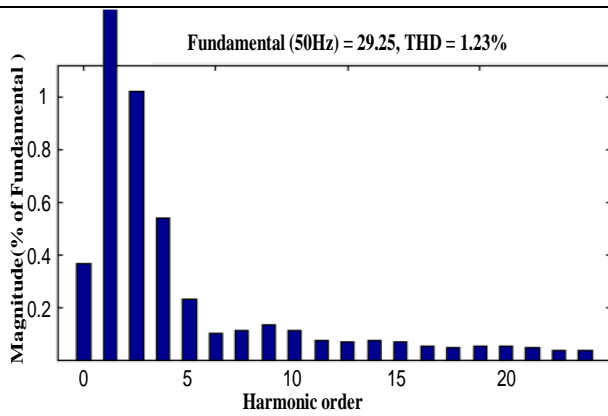

Fig.12 FFT Analysis of Source current

Figures 10, 11 and 12 are obtained from the proposed setup system. The output results obtained by removal of harmonics by Synchronic embedded system show the effectiveness of the proposed theory. From figures 9 and 12, the total harmonic reduction is reduced from $5.61 \%$ to $1.23 \%$.A complete report on this approach is tabulated in Table-VI, contents of harmonics with fundamental percentage [29]. Figures 10, 11 and 12 are obtained from the proposed setup system. The output results obtained by removal of harmonics by Synchronic embedded system show the effectiveness of the proposed theory. From figures 9 and 12, the total harmonic reduction is reduced from $5.61 \%$ to $1.23 \%$.A complete report on this approach is tabulated in Table-VI, contents of harmonics with fundamental percentage [29].

\begin{tabular}{|c|c|c|}
\hline $\begin{array}{c}\text { Order of } \\
\text { Harmonics }\end{array}$ & $\begin{array}{c}\text { Hybrid AP filter } \\
\text { simulations }\end{array}$ & System setup \\
\hline Fundamental & 100 & 100 \\
\hline 3 & 5.48 & 2.22 \\
\hline 5 & 6.19 & 3.99 \\
\hline 7 & 9.44 & 4.03 \\
\hline 9 & 7.32 & 3.01 \\
\hline 11 & 6.25 & 3.08 \\
\hline 13 & 9.22 & 2.05 \\
\hline 15 & 5.17 & 1.03 \\
\hline
\end{tabular}

\section{CONCLUSIONS}

This paper contributes the knowledge of power quality in power system. The paper presents some of the methods as precautionary measure to maintain power quality in power system. Performance of the active filter is measured through the Total Harmonics Distortion in percentage with respect to the fundamental Different power quality phenomenon and the various existing techniques used to enhance the power quality problems are discussed. 


\section{Power Quality Issues in Power Systems}

Some techniques suggested to use Battery supported L-Type shunt active filter with the Control techniques to power quality improvement. It has been observed the Unit vector template control technique with hysteresis current controllers gives encouraging results for reduction of harmonics present in an original signal. Whereas from synchronous detection algorithm implemented with Hybrid AP filter results in the reduction of harmonics to an acceptable level of IEEE standards. It is clear from the above analysis that the use of the controller by connecting two types of loads such as R-L and $\mathrm{R}-\mathrm{C}$, the Magnitude of THD after compensation are considerably reduced.

\section{REFERENCES}

1. Math. H.J.Bollen " Understanding Power Qualkity Problem" A JOHNWILEY \& SONS, INC.,PUBLICATIONH.

2. Padmavathi and K R Sudha, Optimal sizing and placement of Dynamic Voltage Restorer in the Distribution System using Firefly Algorithm, International Journal of Energy Technology and Policy, Vol. 15,No.2/3, pp.148-165, 2019.

3. Report on Power Quality of Electric Supply to the consumers, Report published by Forum of Regulators, August 2018.

4. A Report on "Swachh Power -A Glimpse on Power Quality in India, Published by Power Grid Coroporation in India-2015

5. Akagi, "New trends in active filters for power conditioning", IEEE Transactions on Industry Application, vol .32, pp 1312- 1322, 1996.

6. J.A. Demcko and S.Sullivan, Power quality problems and solutions at Arizona public service company, 7th IEEE Int. Coni onHarmonicsandQuality ofPower (ICHPQ), LasVegas,NV, ,pp.348-353,1996

7. E.W. Gunther andH.Mehta,Asurveyof distribution systempower quality-Preliminary results, IEEE TransactionsonPowerDelivery, vol.10,no.1, pp.322-329,1995

8. M.H.J.Bollen,T. Tayjasajant, andG.Yalcinkaya,Assessmentofthe number ofvoltage sagsexperiencedbyalarge industrial customer, IEEE TransactionsonIndustryApplications,

Vvol..33,no.6 ,pp.1465-1471,1997

9. C. Pumar, J. Amantegui, J. R.Torrealday, and C. Ugarte, A comparison betweenDCand ACdrivesas regards their behaviour inthe presence of voltage dips:New techniques for reducing the susceptibility of ACdrives, Int. Con! on Electricity Distribution fCIRED), , Birmingham, U.K., pp. 5-11, 1997

10. J. Lamoree, D.Mueller,P. Vinett, W. Jones, andM. Samotyj, Voltage sag analysis case studies, IEEE TransactionsonIndustryApplications, vol.30,no.4, ,pp. 1083- 1089,1994

11. H.G. Sarmiento andE. Estrada, A voltage sag study inan industry with adjustable... speed drives, IEEE IndustryApplicationsMagazine, vol.2,no.1, ,pp.16-19,1996

12. J.e. Smith,J. Lamoree, P.Vinett,T. Duffy, and M.Klein,The impact of voltagesagson industrial plant loads, Int. Con! PowerQuality:End-useapplicationsandperspectives $\quad$ (PQA...91), pp.171-178.1995

13. E.G. Strangas, V.E. Wagner, and T.D. Unruh, Variable speeddrives evaluation test, IEEE IndustryApplicationsSociety Annual Meeting, October 1996,SanDiego,CA,pp.2239-2243.Arevisedversion of this paper appeared in IEEE IndustryApplications Magazine, vol.4,no.1, pp.53-57,1998

14. A. David, J.Maire,andM. Dessoude, Influence of voltagedipsandsag characteristics on electricalmachinesanddrives: evaluation andperspective, lrd Int. Con! onPowerQuality: End-use applications and perspectives, , Amsterdam, The Netherlands, 1994

15. E.W. Gunther andH.Mehta,Asurveyof distribution systempower quality-preliminary results, IEEE TransactionsonPowerDelivery, vol.10,no.1, ,pp.322-329,1995

16. R.C.Dugan,M.F. McGranaghan, andH.W.Beaty, ElectricPower Systems Quality, McGrawHill,NewYork,1996

17. W.E.KazibweandM.H.Sendaula,ElectricPowerQualityControlTechniq ues, Van Nostrad Reinhold,NewYork.

18. IEEErecommendedpracticeforpoweringandgroundingsensitiveelectro nicequipment, IEEE Std. 1100-1992.
19. EuropeanstandardEN-50160,

Voltagecharacteristicsofelectricitysuppliedbypublicdis-

tribution systems, CENELEC, Brussels,Belgium, 1994

20. R.N.Allan,R.Billinton, andS.H.Lee,Bibliographyontheapplicationofpr obability methodsinpowersystemreliabilityevaluation1977-1982, IEEE TransactionsonPower Apparatus and Systems, vol.103,no.2, ,pp. $275-282.1984$

21. H.H. Kajihara, Quality powerforelectronics, Electro-Technology, vol.82,no.5, ,pp..46-49,1984

22. W.E.Kazibwe,R.J.Ringlee,G.W.Woodzell,andH.M. Sendaula, Powerquality:A review, IEEE Computer Applications inPower, vol.3,no.1, pp.39-42,1990

23. R. Wilkins and M.H.J. Bollen, Therole of current limitingfusesinpower quality improvement, 3rdInt.Conf.onPowerQuality:End-useapplicationsandperspectives, Amsterdam,1994

24. Lj. Kojovic andS. Hassler, Application of current limitingfusesin distribution systemsfor improved power quality and protection, IEEE TransactionsonPowerDelivery, vol.12,no. 2, pp.791-800,1997

25. P.M. Anderson, Analysis of FaultedPower Systems, NewYork: IEEE Press, 1995

26. J. Holtz, W. Lotzhat, and S. Stadfeld, Controlled ACdriveswith ride-through capacity at power interruption, IEEE TransactionsonIndustryApplications, vol, 30,no.5, September ,pp.1275-1283,1994

27. D.S. Dorr, A. Mansoor, A.G. Morinec, and J. C. Worley, Effects of power line voltage variations on different types of 400 -Whigh pressure sodium ballasts, IEEE Transactionson IndustryApplications, vol.33,no.2, ,pp. 472-476,1997

28. N. Mohan, T.M. Undeland, andW.P Robbins, Power Electronics-Converters, Applications and Design, John WileyandSons,New York, 1995.

29. Pratap Sekhar Puhan, Ravikanth Mallajoshula "Synchro-Embedded Intelligent Based Controller Applied To Hyrid Active Power Filter”.ICICCS2018

\section{AUTHORS PROFILE}

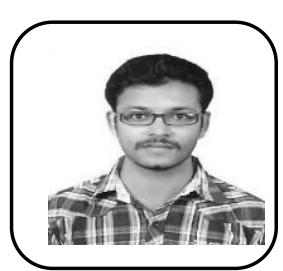

Ravikanth Mallajoshula was born in Hyderabad, India. He received Bachelor in Technology Degree from JNTUH, India. he completed his Masters in engineering from university college of engineering Osmania University in 2013. He is pursuing he $\mathrm{PhD}$ from GITAM university Vishakhapatnam, India.

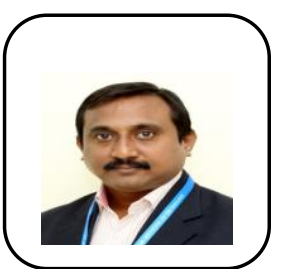

Dr.I.E.S.Naidu received his BTech in Electrical and Electronics Engineering from JNTU, Hyderabad and MTech in Advanced Power Systems from the JNTU, Kakinada in2001 and 2005 respectively. He was awarded Doctorate in Electrical Engineering by Andhra University in 2018. During 2005-2006, he worked with ANITS College and presently he is working as Associate Professor in the Electrical \& Electronics Engineering Department, GITAM Visakhapatnam campus, India. His research interests include power system stability and power system security 